\title{
(2) OPEN ACCESS \\ Measuring the illicit cigarette market in the absence of pack security features: a case study of South Africa
}

\author{
Nicole Vellios $\odot$, Corné van Walbeek $\odot$, Hana Ross
}

Research Unit on the Economics of Excisable Products, School of Economics, University of Cape Town, Cape Town, Western Cape, South Africa

\section{Correspondence to}

Nicole Vellios, Research Unit on the Economics of Excisable Products, School of Economics, University of Cape Town, Cape Town, 7700, South Africa; nicole.vellios@uct.ac.za

Received 24 July 2020 Revised 27 November 2020 Accepted 30 November 2020
D) Check for updates

(C) Author(s) (or their employer(s)) 2021. Re-use permitted under CC BY-NC. No commercial re-use. See rights and permissions. Published by BMJ.

To cite: Vellios $\mathrm{N}$, van Walbeek C, Ross H.

Tob Control Epub ahead of print: [please include Day

Month Year]. doi:10.1136/

tobaccocontrol-2020-056117

\section{ABSTRACT}

There are several ways to measure the illicit cigarette market. In South Africa, different methods were used to triangulate results. The aim of this paper is to assist researchers to decide which method is most suitable to their context, especially for countries that do not have security features on cigarette packs (eg, tax stamps). We analysed the methods and results from three published articles that used various approaches to measure cigarette illicit trade in South Africa: (1) gap analysis, (2) price threshold method using secondary data from a national survey, and (3) price threshold method using primary data collected in low socioeconomic areas. We provide methodological insights and background information. We discuss the advantages and disadvantages of each method. The method chosen by researchers will depend on data availability, the existence or absence of security features on cigarette packs and funding. Researchers investigating illicit trade should use more than one method to increase confidence in the obtained results.

\section{INTRODUCTION}

As in many countries, independent, reliable estimates of illicit trade in South Africa are required to counter industry claims about the size of the illicit market. The industry has an incentive to exaggerate the size of and growth in the illicit market to discourage governments from raising tobacco excise taxes. ${ }^{1}$

A comprehensive methodological guide to measure illicit cigarette trade details the various methods available to researchers, depending on market conditions. ${ }^{2}$ In addition to the methods in this guide, which have been used globally, a new method has been developed (collecting packs from retailers). ${ }^{3}$

Since illicit trade is inherently difficult to measure, results can be triangulated using different methods, as has been done in India, Mexico, and Poland. ${ }^{3-5}$ Despite there being several methods to measure illicit trade, it may be impossible to use them all in a specific country. The method chosen is highly context dependent; each country requires a tailor-made approach.

In South Africa, the choice of method was driven by the absence of any security features (eg, tax stamps) indicating tax payment and because illicit manufacturers comply with health warning requirements.

South Africa uses an antiquated diamond-shaped excise stamp impression (which is barely visible and easy to counterfeit). These stamps are meaningless: in reality, most packs, including illicit packs, bear the diamond stamp. In addition, about one-third of smokers buy their cigarettes as single sticks, therefore collecting and examining littered packs may not adequately estimate the size of the illicit market.

Cigarette packaging laws were last updated in South Africa in $1994 .{ }^{6}$ South Africa only requires a written health warning on the front $(15 \%)$ and back $(25 \%)$ of the pack. The health warning messages have not changed since implementation. Illicit manufacturers comply with these requirements, so warning labels cannot be used to distinguish a legal pack from an illegal one.

Any method that relies on examining packs was therefore infeasible in South Africa. Two methods were selected: (1) gap analysis and (2) the price threshold method. For the price threshold method, prices were obtained in two different ways: (a) from a nationally representative household survey (secondary data), and (b) from a survey of smokers in low socioeconomic areas (primary data).

This paper provides a practical guide on how to measure illicit trade in countries where pack observation methods are infeasible. This paper is based on three standalone academic articles. ${ }^{7-9}$ Table 1 provides a summary of the three articles, including sample sizes, years covered, data, results, advantages, disadvantages, and practical tips.

\section{Gap analysis}

Gap analysis compares self-reported consumption estimates (from national survey data) with legal sales (as declared to the excise tax authority). The gap is the difference between total self-reported consumption and legal sales, which approximates the illicit market.

To calculate self-reported consumption, one requires data on smoking prevalence (which is used to calculate the total number of smokers in a population) and smoking intensity (the average number of cigarettes smoked in a time period). Annual selfreported consumption is calculated by multiplying the number of smokers by the average number of cigarettes smoked per day, multiplied by 365 . Survey weights allow researchers to scale these estimates to represent the entire population.

Gap analysis results can be presented as trends over time, as absolute numbers, or as a percentage of the total market. Although reporting the percentage is more desirable for policymakers and other stakeholders, it comes at a price: the necessity to make assumptions about under-reporting. Since people tend to under-report socially undesirable behaviours, ${ }^{10-12}$ self-reported cigarette consumption needs to be adjusted. Reported cigarette consumption may also be affected by question wording, questionnaire content, and sampling 


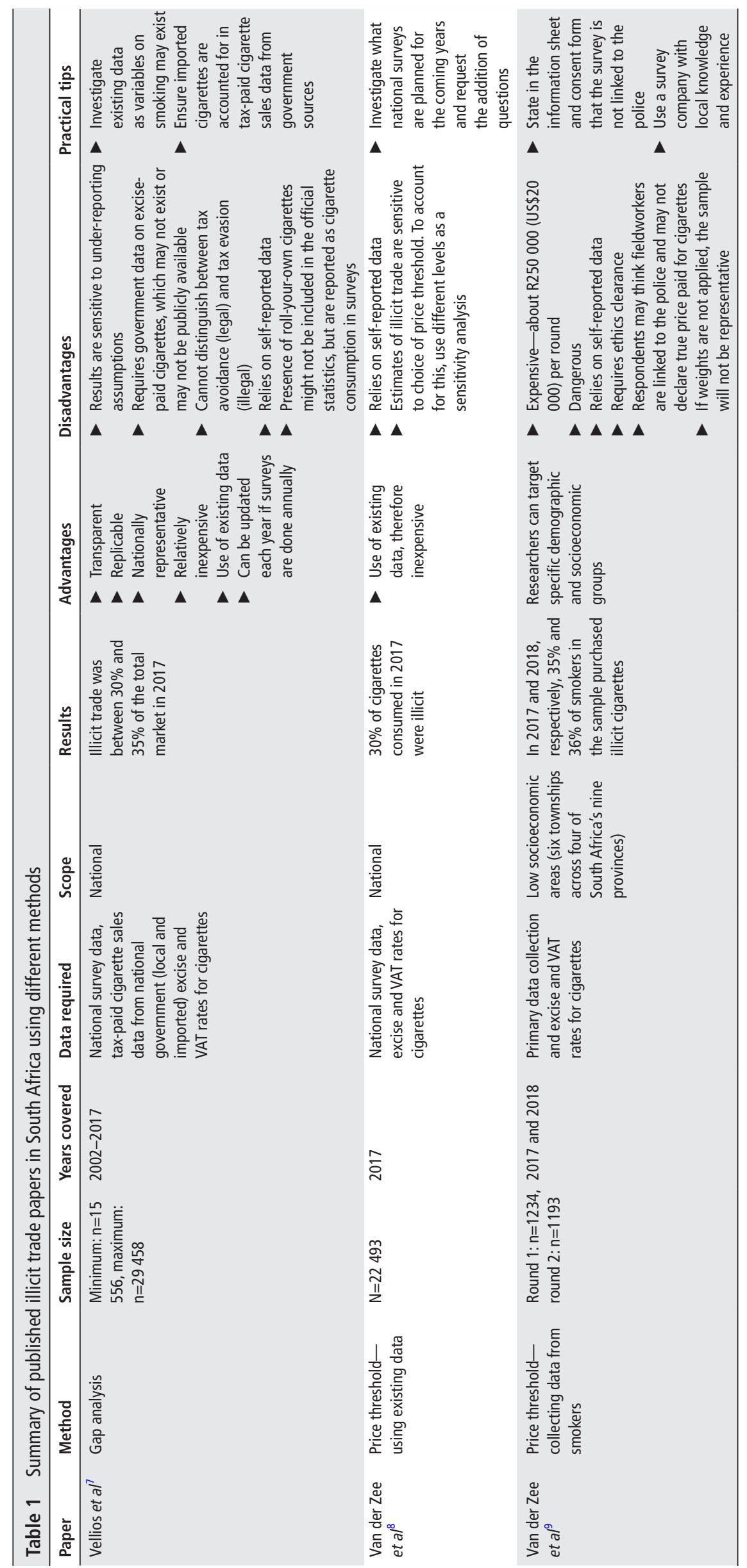


methodologies. Under-reporting captures these inconsistencies. If researchers require illicit trade estimates as a percentage of the total market, then there are two unknowns: the level of illicit trade and the level of under-reporting in the survey data.

Self-reported consumption should be equal to or greater than tax-paid consumption in all years, to ensure that the volume of illicit trade is not less than zero, since negative illicit trade is illogical. Researchers should not be concerned if illicit trade is less than zero before self-reported consumption is adjusted to account for under-reporting. Under-reporting estimates have a direct impact on the estimated size of the illicit market and should therefore be carefully considered. The level of underreporting can be calculated if there is a year when illicit trade was insignificant. Let $\mathrm{x}$ be self-reported consumption and $\mathrm{y}$ be actual consumption:

$$
\mathrm{y}=\frac{\mathrm{x}}{100 \%-\text { under-reporting percentage }}
$$

If $\mathrm{x}$ and $\mathrm{y}$ are known, then the percentage of under-reporting can be calculated. For example, if actual consumption (y) is 100 cigarettes, but a smoker reported 70 cigarettes, then this smoker has under-reported his/her true consumption by 30 cigarettes (30\%). This estimate can be used to calculate actual consumption for subsequent years $(y=x / 0.7)$. If a $30 \%$ increase is applied to the 70 units, actual consumption would be underestimated at 91 cigarettes $(70 \times 1.3)$ versus the more accurate number of 100 (70/0.7). An alternative method is to apply an uplift factor to selfreported consumption. Using the same example, the uplift factor would be 1.43 (based on the calculation $1 /((100-30) / 100))$.

The latter application is used by Her Majesty's Revenue and Customs, who apply an uplift factor of 1.46 to self-reported consumption. This implies that 100 self-reported cigarettes are increased to 146 actual cigarettes. The survey therefore captured $68.5 \%$ of smokers' consumption $(x=100 / 146)$. The assumption is that under-reporting is $31.5 \%$ (100\%-68.5\%).

The same under-reporting estimate can be used for all years. If there is reason to believe that under-reporting is increasing or decreasing, the researcher may consider using different underreporting estimates for different years. It may be important to periodically validate and, if appropriate, modify under-reporting estimates. While most researchers apply the same underreporting estimates to the entire population, Szklo et al stratified under-reporting by educational level ( $<8$ years vs $\geq 8$ years). ${ }^{13}$

If there is more than one survey covering the same period, different under-reporting estimates by survey may be necessary, depending on how well the surveys capture self-reported consumption. Vellios et al assumed under-reporting is consistent over time and used under-reporting estimates of $5 \%$ and $10 \%$ for the All Media and Products Survey and 15\% and 20\% for the National Income Dynamics Study (NIDS). ${ }^{7}$ These percentages ensure that the volume of illicit trade is not less than zero in any year.

By using different levels of under-reporting, authors can provide a range within which the level of illicit trade is likely to fall. Vellios et al, using 2017 NIDS data, estimated that illicit trade comprised between 30\% (assuming 15\% under-reporting) and 35\% (assuming 20\% under-reporting) of the total market. ${ }^{7}$

Neither of the surveys used in Vellios et al were designed specifically to measure smoking behaviour, yet they ask useful smoking-related questions. Before surveying smokers, researchers should investigate existing datasets as variables on smoking may exist.

The ease or difficulty of obtaining data on legal sales varies across countries. Most countries publish legal sales on the basis of sales declarations by cigarette manufacturers for tax purposes.
If the revenue service is interested in illicit trade, they may be helpful in accessing data gatekeepers.

If it is not possible to get data directly from government sources, researchers can use data from market research firms such as Euromonitor International ${ }^{14}$ and GlobalData. ${ }^{15}$ Paraje used sales information from Euromonitor International since there is no official information on registered sales for Chile, Colombia, and Peru. ${ }^{16}$ However, market-research data are expensive: the 2019 report on the cigarette market in South Africa is $\$ 975$ (GlobalData) and $\$ 990$ (Euromonitor International). The reports cover a variety of topics: historic cigarette sales being one of them.

Comparing sales data from multiple sources provides assurance (or not) as to the accuracy of data. Paraje is the first author to publish illicit trade results for Argentina and Brazil using two sources of legal sales data (government and Euromonitor International). ${ }^{16}$

For South Africa, data on legal sales were derived from budget review statistics, available online. The National Treasury of South Africa compiles excise revenue from domestic cigarette sales. Since excise taxes are levied as a uniform specific tax, the number of cigarettes sold is calculated by dividing the excise revenue by the excise tax per cigarette. Excise revenue from imported cigarettes may be captured separately from locally produced cigarettes (as is the case in South Africa). In South Africa, the number of cigarettes imported was sourced from the Department of Trade and Industry's website, as the budget line for imported cigarettes is aggregated with other imported products. Excluding imports results in higher illicit trade estimates since the gap between tax-paid sales and self-reported consumption is wider.

A long-time trend allows researchers to benchmark their results with previous academic studies and explain discrepancies, if any. Vellios et al compared their results to two previous studies, namely Van Walbeek and Blecher. ${ }^{17} 18$

The advantages of the gap analysis method are that the results are transparent, replicable, and nationally representative. Results can be updated as new data become available. As secondary data are used, this method is relatively inexpensive.

The gap analysis method has a number of disadvantages. First, the results are sensitive to the under-reporting assumptions. Second, government data on legal cigarette sales may be unavailable. Third, this method cannot distinguish between tax avoidance (legal) and tax evasion (illegal). Tax avoidance occurs when smokers legally buy cigarettes in neighbouring countries with a lower tax rate. These smokers will report smoking in surveys (which assumes local purchases), but the cigarettes they bought will not appear in government tax-paid sales data. Fourth, rollyour-own cigarettes might not be included in official statistics, but are reported in surveys. Consequently, the comparison of survey-based consumption (that includes roll-your-own cigarettes) with tax-based sales would overestimate the level of tax evasion/avoidance. ${ }^{2}$ Fifth, gap analysis does not account for cigarette packs that, having paid excise tax, subsequently leave the country.

\section{Price threshold}

The price threshold method identifies a price point that separates legal cigarettes from illegal cigarettes. In the market, the final price of cigarettes is the sum of manufacturing costs, taxes (excise, Value Added Tax (VAT) and possibly other duties), distribution costs (producer, wholesaler, and retailer), and profits. A price threshold is determined, below which it is impossible to sell 
the product and cover all costs. The price threshold method has previously been used in South Africa, ${ }^{19}$ Brazil $^{20}$ and Colombia. ${ }^{21}$

The crucial variable for the price threshold method is the price paid by smokers the last time they bought cigarettes. In the absence of minimum price legislation, it is possible that companies sell fully tax-paid cigarettes at a price below the price threshold (eg, in order to gain market share), but such a pricing strategy would be unsustainable for any length of time.

In South Africa, a specific excise tax is applied to every pack of 20 cigarettes, irrespective of brand, price or other features. In 2017, the excise tax on a pack of 20 cigarettes was R14.30 and the 14\% VAT on excise was R2.00 (total tax of R16.30). Evidence from the South African tobacco industry suggests that in 2017 , it cost R2.50 to produce a pack of cigarettes. ${ }^{22}$ If one adds the 14\% VAT on R2.50 (R0.35), the total is R19.15. Information on distribution costs and profits (at the producer, wholesale and retail level) were unavailable. These expenses (and the VAT on them) are not included in the price threshold calculation. The price threshold was set at R20 per pack of 20 cigarettes (R1 per stick). Reporting illicit trade estimates by packaging type (single, 10-pack, 20-pack, 30-pack, carton) is important especially in countries where single sticks are widely available, as illicit trade estimates may differ by packaging type. In South Africa, the proportion of cigarettes sold for R1 or less per stick is highest for cartons, while the proportion is similar for those sold in packs of 20 cigarettes and those sold as singles.

The price threshold method may be more challenging in countries where the proportion of single sticks users is high, as single stick vendors may charge higher retail margins (even for illicit cigarettes). This is not problematic in South Africa as the informal market is competitive.

It is important to distinguish between the proportion of smokers who buy illicit cigarettes versus the proportion of illicit cigarettes consumed in the total market. Both can be done using the price threshold method (the latter requires information on smoking intensity). The proportion of smokers who buy illicit cigarettes will be lower than the proportion of illicit cigarettes consumed in the total market if people who smoke illicit cigarettes smoke more than people who do not smoke illicit cigarettes.

Estimates of the proportion of smokers who buy illicit cigarettes versus the proportion of illicit cigarettes in the total market may reach different audiences and serve different purposes. Estimates of the proportion of smokers may be useful to understand the health impacts in smokers who, instead of quitting, switch to cheaper illicit cigarettes. Switching to illicit cigarettes undermines the effectiveness of tax and price policies, and, consequently, increases healthcare costs and lowers productivity. The proportion of illicit cigarettes in the total market assists the revenue service, who are responsible for collecting excise revenue and tackling illicit trade.

Researchers may need to clean the data to remove outliers. Respondents may incorrectly report prices because they have misunderstood the questions. For example, a smoker who reported buying five packs of cigarettes (20-pack) at their most recent purchase for R10 in total probably misunderstood the question and answered giving the price per pack (instead of total expenditure). The importance of asking questions clearly to avoid these errors cannot be overemphasised. However, even the most clear wording results in some errors. Researchers can use knowledge of the market and other datasets if they exist. In South Africa, another dataset, the African Cigarette Prices datase $\mathrm{t}^{23}$ was used to ascertain the range of cigarette prices that made economic sense. An appendix that shows the 'rules' that were applied to clean the data can be added to provide additional information and to ensure that the results are replicable.

Brand information can be used to understand the different types of illicit practices in a market. For example, if a brand is produced in Zimbabwe, but there are no records that this brand is exported to South Africa and it has not been brought into South Africa by a Zimbabwean tourist, then it was probably smuggled into South Africa. A brand produced and sold locally at low prices indicates tax evasion, as is the case in South Africa. $^{24}$

Data collected from respondents suffer from the disadvantage that respondents may not answer questions accurately. Respondents who are smokers may not admit to it. Consumers who purchase illicit cigarettes may not state the true price they paid. Under-reporting, which may differ by socioeconomic status, results in underestimating illicit trade. With a dedicated tobacco survey, under-reporting may be higher as respondents are aware that the focus is on smoking behaviour (compared with national surveys that cover many different topics).

\section{Secondary data: using existing data}

Van der Zee et al, using NIDS wave 5 (conducted in 2017), estimated the proportion of illicit cigarettes consumed in the total market. ${ }^{8}$ To do this, information on smoking intensity and survey weights are required.

In the planning stages of wave 5 , the NIDS team was asked to include the following questions: "When you last purchased cigarettes, what size was the packaging?', 'How many of these packs (or single sticks) did you buy when you bought your cigarettes?', and 'How much did it cost you to buy these cigarettes?'

Researchers should investigate what national surveys are planned for the coming years and request the addition of questions. Adding questions to national surveys is ideal, as it may cost little or nothing. This was the case in South Africa, but this may not be the case in other countries. The main advantage is that the results are nationally representative. Using data from national surveys allows researchers to include variables like education and income in the analysis.

\section{Primary data: collecting new data}

Collecting new data allows researchers to tailor the survey to their research question. Since smokers are the only consumers involved in purchasing cigarettes, only smokers (not the general population) should be sampled. Obtaining guidance from a statistician will improve the sampling frame. The rigour of the sampling methodology will depend on budget availability. If budgets are limited, then simple methods may be the only option. Van der Zee et al could not apply a rigorous sampling methodology due to budget constraints and safety issues. Instead, they used a random walk approach in six townships to estimate the proportion of smokers who buy illicit cigarettes. ${ }^{9}$

Understanding the local context is key when deciding where to recruit respondents. It is useful to speak to colleagues and survey companies who have collected data in specific areas. There may be areas that have been sampled many times, which results in low response rates due to respondent fatigue. There may also be areas that are crime hotspots.

Data used in Van der Zee et al, collected by different survey companies in round 1 and round 2, were captured using electronic tablets operationalised on the SurveyCTO platform. ${ }^{9}$ The companies were responsible for recruiting fieldworkers, uploading the questionnaire on SurveyCTO, questionnaire piloting, executing and implementing the survey, ensuring 
quality control (including telephonic back checks), and compiling field reports. A household questionnaire was used to screen for smokers. An individual questionnaire was completed by a randomly selected smoker in those households willing and available to participate. Households were surveyed until a target of 200 smokers per township was reached.

Differences in socioeconomic status and smoking behaviours between individuals living in households willing and available to participate and the true population may bias illicit trade estimates. For instance, individuals who smoke more cigarettes per day (who perhaps smoke more illicit cigarettes) tend to be more often out on the streets and may have a higher chance of selection in the random walk approach.

If different companies are used, the method in subsequent rounds should resemble that of the first to ensure comparability. Van der Zee $e t$ al ensured that data in both rounds were collected over a short period (round 1: October-November 2017, round 2: July-August 2018). Data were collected over periods unaffected by any policy changes (such as excise tax increases). Data were not collected over the December/January period to avoid any seasonal variation in cigarette consumption (such as New Year's resolutions).

To improve the likelihood of people being truthful about their smoking habits, especially in the context of illicit activities, it was important in the South African context to inform participants upfront that the survey was not linked to the police. If respondents who buy illegal cigarettes think that they may be caught, they will refuse to participate or give incorrect information. In countries where people may be embarrassed to disclose that they smoke illicit cigarettes, illicit trade estimates may be severely underestimated. In South Africa, this was not problematic as many smokers are unaware that they are purchasing illicit cigarettes. Those who are aware are probably unconcerned as the consequences are negligible.

Weighting data can add additional rigour to survey results. Van der Zee et al did not apply weights because weighting data required robust sampling (which was not possible due to budget constraints) and because the actual population estimates from which the sample was drawn was unknown. To account for this limitation, the authors present the results as an observational study: $34.6 \%$ and $36.4 \%$ of smokers in the sample purchased illicit cigarettes. The authors do not report illicit trade estimates in townships or in low socioeconomic areas.

Questionnaires and data can be made publicly available, which enables other researchers to replicate the results or to explore other research questions. The questionnaires and data from Van der Zee are publicly available. ${ }^{25}$ A paper that describes data collection, all the variables in the dataset, and other research topics the data can be used for is also publicly available. ${ }^{26}$

A major disadvantage of collecting data in low socioeconomic areas in South Africa is crime. This may or may not be similar in other countries. During round 1, fieldworkers entered houses where cocaine was being produced, others were robbed of their personal belongings. One fieldworker, who was born and raised in the area where she was conducting fieldwork, said her biggest fear entering people's homes was being raped. In some areas, fieldworkers recruited participants on the streets to avoid entering people's homes. In round 2, the survey company had inside information about crime hotspots from previous fieldwork experience in these areas. The survey company also had better contact and communication with community leaders, who were instrumental in advising against certain areas. Despite this, one fieldworker was robbed of his belongings and his survey tablet, and a team supervisor reported that he narrowly avoided being hijacked.

\section{DISCUSSION}

Choosing a method to measure illicit trade is limited by data availability, the existence of security features on cigarette packs, and budget constraints. The optimal practice for researchers studying illicit trade is to cross-validate their estimates using different methods. ${ }^{4}$

The estimates of South Africa's illicit market, using different methods, were close. In 2017, illicit trade estimates (percentage of the total market and percentage of smokers who buy illicit cigarettes) ranged from $30 \%$ to $36 \%$. Using gap analysis, illicit cigarettes comprised between $30 \%$ and $35 \%$ of the total market. ${ }^{7}$ Using the price threshold method with secondary data, illicit cigarettes accounted for approximately 30\% of the market in $2017 .{ }^{8}$ Primary data were also collected, which focused on low socioeconomic areas. In 2017 and 2018, respectively, 35\% and $36 \%$ of smokers in the sample indicated that they had purchased illicit cigarettes, based on the prices paid for the product. ${ }^{9}$

These results are surprisingly close to those of the tobacco industry who surveyed 2058 outlets twice. They estimated that illicit trade as a percentage of the total market was $27 \%$ in June 2018 and 33\% in September 2018 using a different price threshold. ${ }^{27}$ They defined illicit trade as any product whose price was less than the excise tax plus the VAT (a total of R17.85 per pack of 20 cigarettes or $90 \mathrm{c}$ per single cigarette).

It is important to keep monitoring changes in the illicit market. Researchers should keep track of when new national survey data are released. These data can be used to update the gap analysis and the price threshold method. In addition to monitoring illicit trade, countries should have a sustained surveillance system to track tobacco use, as outlined in Article 20 of the WHO's Framework Convention on Tobacco Control.

Understanding the causes of illicit trade can be achieved by conducting qualitative research with revenue services. In the case of South Africa, several books have been written by an investigative journalist ${ }^{28}$ and an ex-government employee..$^{24}$

Results from academic papers can be used to argue for better tax administration to curb illicit trade. Results can be disseminated through the media, directly emailing relevant government officials (accompanied by a one-page or two-page summarised policy brief), and presenting results to various stakeholders.

The WHO's Protocol to Eliminate Illicit Trade in Tobacco Products provides best practices for eliminating illicit trade. ${ }^{30}$ Tackling illicit trade is also addressed in a World Bank report that provides multiple country-specific examples. ${ }^{31}$

\section{CONCLUSION}

While there are several methods available to researchers to measure illicit trade, the choice is country specific. Researchers

What this paper adds

- The paper provides practitioners with a guide on how to measure illicit trade in countries that do not have tax security features, using South Africa as a case study.

- South Africa provides a good example of how researchers were creative in applying different methods to measure illicit trade.

- The advantages and disadvantages of the gap analysis and price threshold method are discussed. 
need to understand the regulatory environment (eg, cigarette packaging laws) and investigate available data sources (and assess data accuracy). In South Africa, a variety of possible methods were used to estimate illicit trade. This allows a level of confidence in the results that would have been lacking if only one method had been used.

Contributors NV conceptualised and drafted the first version of the paper. All authors contributed to the writing of the manuscript.

Funding This research was supported by the International Development Research Centre under the Global Alliance for Chronic Diseases research programme (grant ID number: 108442-002 and IRMA 25761), Cancer Research UK (IRMA 25171), and the Bill and Melinda Gates Foundation (through the African Capacity Building Foundation) (IRMA 20177).

Competing interests None declared.

Patient consent for publication Not required.

Provenance and peer review Not commissioned; externally peer reviewed.

Open access This is an open access article distributed in accordance with the Creative Commons Attribution Non Commercial (CC BY-NC 4.0) license, which permits others to distribute, remix, adapt, build upon this work non-commercially, and license their derivative works on different terms, provided the original work is properly cited, appropriate credit is given, any changes made indicated, and the use is non-commercial. See: http://creativecommons.org/licenses/by-nc/4.0/.

\section{ORCID iDs}

Nicole Vellios http://orcid.org/0000-0003-1488-0179

Corné van Walbeek http://orcid.org/0000-0003-0933-435X

Hana Ross http://orcid.org/0000-0001-5799-1915

\section{REFERENCES}

1 Smith KE, Savell E, Gilmore AB. What is known about tobacco industry efforts to influence tobacco Tax? A systematic review of empirical studies. Tob Control 2013;22:e1-53.

2 Ross $\mathrm{H}$. Understanding and measuring tax avoidance and evasion: a methodological guide. Prepared for the Economics of Tobacco Control Project, School of Economics, University of Cape Town and Tobacconomics, Health Policy Center, Institute for Health Research and Policy, University of Illinois at Chicago; 2015.

3 John RM, Ross H. Illicit cigarette sales in Indian cities: findings from a retail survey. Tob Control 2018;27:684-8.

4 Saenz de Miera Juarez B, Reynales-Shigematsu LM, Stoklosa M, et al. Measuring the illicit cigarette market in Mexico: a cross validation of two methodologies. Tob Control:tobaccocontrol-2019-055449.

5 Stoklosa M, Ross H. Contrasting academic and tobacco industry estimates of illicit cigarette trade: evidence from Warsaw, Poland. Tob Control 2014;23:e30-4.

6 Republic of South Africa. Regulations relating to the labelling, advertising and sale of tobacco products as published in GN 2063 in GG 16111 of 2 December 1994 as amended by GN R1148 in GG 16588 of 4 August 1995: 1995.

7 Vellios N, Ross H, Van Walbeek C. The illicit trade of cigarettes in South Africa: 2002 2017. Tob Control 2019;29.

8 Van der Zee K, Van Walbeek C, Magadla S. Illicit/cheap cigarettes in South Africa. Trends Organ Crime 2020;23:242-62.

9 Van der Zee K, Vellios N, Van Walbeek C, et al. The illicit cigarette market in six South African townships. Tob Control 2020;29:s267-74.
10 Dietz PM, Homa D, England LJ, et al. Estimates of nondisclosure of cigarette smoking among pregnant and nonpregnant women of reproductive age in the United States. Am J Epidemiol 2011;173:355-9.

11 Pérez-Stable EJ, Marín BV, Marín G, et al. Apparent underreporting of cigarette consumption among Mexican American smokers. Am J Public Health 1990;80:1057-61.

12 Roth MA, Aitsi-Selmi A, Wardle H, et al. Under-reporting of tobacco use among Bangladeshi women in England. J Public Health 2009;31:326-34.

13 Szklo A, Iglesias RM, Carvalho de Souza M, et al. Trends in illicit cigarette use in Brazil estimated from legal sales, 2012-2016. Am J Public Health 2018;108:265-9.

14 Euromonitor international, 2020. Available: https://www.euromonitor.com/search? txtSearch=cigarette

15 GlobalData, 2020. Available: https://store.globaldata.com/search/?s=cigarette

16 Paraje G. Illicit cigarette trade in five South American countries: a gap analysis for Argentina, Brazil, Chile, Colombia, and Peru. Nicotine Tobacco Research 2019;21:1079-86.

17 Van Walbeek C. Measuring changes in the illicit cigarette market using government revenue data: the example of South Africa. Tob Control 2014;23:e69-74.

18 Blecher E. A mountain or a molehill: is the illicit trade in cigarettes undermining tobacco control policy in South Africa? Trends Organ Crime 2010;13:299-315.

19 Liedeman R, Mackay B. A Smokescreen economy: the nature and scale of the township grey market cigarette trade in Delft, 2015. Available: http://livelihoods.org za/wp-content/uploads/2018/05/A-Smokescreen-Economy-township-grey-marketcigarette-trade-in-Delft_booklet.pdf

20 Iglesias RM, Szklo AS, Souza MCde, et al. Estimating the size of illicit tobacco consumption in Brazil: findings from the global adult tobacco survey. Tob Control 2017;26:53-9.

21 Maldonado N, Llorente BA, Iglesias RM, et al. Measuring illicit cigarette trade in Colombia. Tob Control 2018. doi:10.1136/tobaccocontrol-2017-053980. [Epub ahead of print: 14 Mar 2018].

22 Biznews. Alec Hogg interwiews owner of Amalgamated Tobacco. Meet 'half pregnant' Yusuf Kajee - independent tobacco player with strong Zuma connection, 2017. Available: https://iono.fm/e/883933

23 Research Unit on the Economics of Excisable Products. Data on Alcohol and Tobacco in Africa Project. African Cigarette Prices 2016-2019. [dataset]. Version 1.3. Cape Town: Research Unit on the Economics of Excisable Products [producer], 2019. Cape Town: DataFirst [distributor], 2020.

24 Van Loggerenberg J. Tobacco wars. Cape Town, South Africa, Tafelberg: NB Publishers, 2019.

25 Research Unit on the Economics of Excisable Products. South Africa - Township Smoking Study 2017-2018 [dataset]. Version 1. Cape Town: Research Unit on the Economics of Excisable Products (REEP) [producer], 2020. Cape Town: DataFirst [distributor], 2020.

26 Vellios N, Van der Zee K. Dataset on cigarette smokers in six South African townships. Data Brief 2020;32:106260.

27 Ipsos. Research report September, 2018. Available: https://web.archive.org/web/ 20190311091719/http:/www.tobaccosa.co.za/wp-content/uploads/lpsos-TobaccoMarket-Study-REPORT.pdf

28 Pauw J. The President's Keepers. NB Publishers, 2017.

29 Van Loggerenberg J, Lackay A. Rogue: The Inside Story of SARS's Elite Crime-busting Unit. Jonathan Ball Publishers, 2016.

30 World Health Organization. Framework Convention on Tobacco Control. Protocol to eliminate illicit trade in tobacco products. Geneva, Switzerland, 2013.

31 World Bank. Confronting illicit tobacco trade: a global review of country experiences. WBG global tobacco control program, 2019. Available: http://documents.worldbank. org/curated/en/677451548260528135/Confronting-Illicit-Tobacco-Trade-a-GlobalReview-of-Country-Experiences 